\title{
Violence and Attribution Error in Adolescent Male and Female Delinquents
}

\author{
Vicki L. Waytowich \\ Kids 'N Care, System of Care Initiative, Jacksonville, FL \\ Anthony J. Onwuegbuzie \\ Department of Educational Leadership and Counseling \\ Sam Houston State University, USA \\ Box 2119, Huntsville, Texas 77341-2119 \\ E-mail: tonyonwuegbuzie@aol.com \\ Salman Elbedour \\ Howard University, USA
}

\begin{abstract}
The purpose of this study was to assess the prevalence of violence attribution errors among female adolescent delinquents in the United States. Also of interest was to compare female delinquents' violence attribution error rate to that of their male counterparts who were participating in the same delinquency intervention programs. A third purpose was to identify predictors (i.e., attitudes toward violence, peer victimization, self-esteem, demographic variables) of violence attribution errors. Participants were 181 juvenile delinquents $(28.2 \%$ female) who participated in two delinquency intervention programs located in Florida during the 2005-2006 year. Findings revealed no statistically significant difference in violence attribution error rate between male (52.7\%) and female (46.5\%) juvenile delinquents. A multiple regression analysis identified six variables that predicted the violence attribution error rate. The Implications of the findings are discussed.
\end{abstract}

Keywords: Violence, Violence attribution error, Attitudes toward violence, Peer victimization, Self-esteem, Juvenile delinquents, Female adolescent delinquents, Male adolescent delinquents 
In the field of social psychology, considerable interest has centered on the mediating role of the causal attributions and assumptions made by the victims and perpetrators of violence (Fondacaro \& Heller, 1990; Shaver \& Drown, 1986; Trachtenberg \& Viken, 1994). However, few of these studies have focused on delinquent female adolescents; in fact, relatively little is known about female delinquents. Indeed, in general, we know very little about the psychology and cognitive/attributional processes of young women in regard to violence (Chesney-Lind \& Sheldon, 1998), perhaps because the prevalence of this group in the criminal population has only recently been considered as serious problem.

\section{Attribution Theory}

Attribution theory is concerned with the cognitive processes that individuals use to justify the events that occur in their social and physical environments (Kelley, 1973). As described by Heider (1958), Jones and Harris (1967), Kelley (1973), and Weiner (1985), individuals operate in the social environment through action, and the process of assigning causes to their actions and experiences is called causal attribution. People set goals, make decisions, and plan activities based on their sociopsychological analysis and appraisal of their past actions, in a dynamic interplay both internally and in relationship with other individuals (Janoff-Bulman, 1979; Janoff-Bulman \& Frieze, 1983; Silver, Wortman, \& Klos, 1982). These causal attributions determine how a person will interpret a given event, by identifying the location of its cause (i.e., internal or external to the individual), the stability of the cause over time (i.e., transient or lasting; Kelley, 1973), and the responsibility for the event (i.e., whether or not the cause is seen as under the individual's control; Abramson, Seligman, \& Teasdale, 1978; Wortman \& Dintzer, 1978). The resulting appraisal is incorporated into the individual's motivational dynamics. An appraisal of something as a good for action becomes a move to action, or motivation (Arnold, 1962). In this way, an individual's subjective assessments may strengthen or weaken the person's motivation to achieve a particular objective.

It is by making attributions that people justify their own behaviors and make sense of them. When recognized, these attributions also can predict future behaviors (Heider, 1958; Jones \& Harris, 1967; Kelley, 1973; Weiner, 1985). According to Bulman and Wortman (1977), Fincham, Beach, and Baucom (1987), Grills and Ollendick (2002), Janoff-Bulman (1979), and other researchers, people are more likely to experience distress that contributes to depression when they attribute their behavioral outcome to personality traits or dispositional characteristics (characterological attributions). Greater mental health benefits are found in people who attribute their problems to some aspect of their own behaviors or to situational factors. An individual's framework of attribution can be a window through which we can view the person's emotional vulnerability self-image, and his/her approach to solving social and interpersonal problems (Jones \& Nisbett, 1972; Lazarus \& Launier, 1978),

The self-questioning involved in the attribution process is also accompanied by inhibitory responses that function quite apart from these appraisals and assumptions. It is the brain's inhibitory response capability that allows people to tolerate, cope with, and master their impulses. As a result, these causal attributions are not necessarily rational or objective; they 
are influenced by the individual's cognitive and sociocultural biases, which include the following: (a) cognitive heuristics, which represent problem-solving strategies that reduce the complexity of making probabilistic judgments (Kahneman, Slovic, \& Tversky, 1982; Nisbett \& Ross, 1980), and which, as noted by Tversky and Kahneman (1974, p. 1124), "are quite useful, but sometimes they lead to severe and systematic errors"; (b) the just world theory, which represents the underlying belief that life is fundamentally "fair" and might influence individuals to view victims as being responsible for their own circumstances (Lerner, 1970, 190); (c) the fundamental attribution error. whereinpersonal or dispositional factors are overemphasized and situational and environmental factors are underemphasized (Tetlock, 1985); (d)

defensive attribution bias, wherein a person's tendency to blame another person increases as the observer's perceived similarity to the other person's circumstances decreases (cf. Burger, 1981); and (3) stereotyping, which occurs as a direct result of the out-group homogeneity, wherein people tend to assign the cause of undesirable behavior by an out-group member to a personal deficiency that they attribute to all members of that group (cf. Fiske, 2000).

Taken together, these cognitive and motivational biases provide the support framework for the individual's patterns of moral and social behavior. Although research on attribution theory in the context of violence and victimization has gained prominence recently, little attention has been paid to the role that attribution plays in placing adolescents at risk for perpetrating acts of violence-especially the role played by violence attribution error.

Because of gendered socialization processes, the differing social status of men and women, and the fact that victim blaming is more common in certain cultures, female juvenile delinquents may show different violence attribution errors than do male juvenile delinquents. Research on this topic is becoming increasingly urgent because the rates of female crime have risen dramatically in recent years. Chesney-Lind (2001) cites federal statistics that the rate of female violent crime has increased more than 100\% since 1981; between 1989 and 1998 the arrest rate for female adolescents increased 50.3\% (compared to $16.5 \%$ for males), and during the same period there was a $64.3 \%$ increase in arrests of females for serious violent offenses. According to a report by the U.S. Department of Justice, in 1999, there were 2.1 million female violent offenders, representing $14 \%$ of all violent offenders (U.S. Department of Justice, Office of Justice Programs, 1999).

There are limited data on attribution errors among female delinquents; however, several studies exist in the area of attribution errors among delinquents. For example, Daley and Onwuegbuzie (1995) documented that $80 \%$ of male juvenile delinquents make inaccurate causal attributions when explaining the violent actions of others. In a later study, Daley and Onwuegbuzie (2004) coined the term "violence attribution error." A specific form of attribution error, this refers to "errors that occur when an offender does not blame the perpetrator of a violent act (e.g., rape) but instead blames either the victim or the circumstance" (p. 551).

In the only study, to date, investigation the violence attribution errors of females, Daley and Onwuegbuzie (1999) compared male $(n=73)$ and female $(n=80)$ high schools students with 
respect to violence attribution errors. These researchers found that females tended to make significantly fewer violence attribution errors (i.e., "errors that occur when an offender does not blame the perpetrator of a violent act (e.g., rape) but instead blames either the victim or the circumstance"; Daley \& Onwuegbuzie, 2004, p. 551) than did their male counterparts. The effect size $(d=0.63)$ associated with this difference was moderate-to-large. More recently, using a mixed-method analysis, Daley and Onwuegbuzie (2004) reported that the male juvenile offenders, who were incarcerated at a correctional facility in a large southeastern U.S. state, committed violence attribution errors approximately $53 \%$ of the time. Although Daley and Onwuegbuzie (2002/2003, 2004) provided evidence that violence attribution errors play an important role in predicting at-risk behaviors, their studies only involved male delinquents. Yet, it is likely that violence attribution errors also place females at-risk for delinquency. However, this possible link has yet to be investigated. This was a subject of the current investigation.

In addition to gender, examining race as a static criminogenic factor (i.e., a factor identified by research as a predictor of crime or criminality) also is poignant due to the over-representation of minority youth currently involved in the juvenile justice system (Florida Department of Juvenile Justice, 2006). Minority youth disproportionately experience a greater degree of violent victimization and perpetration, with homicides accounting for the leading cause of death among African-American males and females between the ages of 15 and 24 years (Commission for the Prevention of Youth Violence, 2000). In 1997, minorities represented $24 \%$ of the juvenile population, yet were $67 \%$ of the juveniles incarcerated in detention facilities (Commission for the Prevention of Youth Violence, 2000). Furthermore, in 2003, African-American youth were more at risk than were White youth, and three times as likely as were youth of other races to be victims of serious violent crime (Federal Interagency Forum on Child and Family Statistics [FIFCFS], 2005). Findings from other studies indicate that gender and race differ across groups in their rates of violence, and that gender and race groups are differentially exposed to protective and risk factors that contribute or ameliorate the risk of violence exposure (Herrenkohl, Hill, Chung, \& Catalano, 2004).

With these variables in mind, a second central purpose was to identify predictors (i.e., peer victimization, self-esteem, and demographic variables) of violence attribution errors. Although numerous studies have been conducted on key indicators of risk that identify a youth to be on a potential path to delinquency such as poverty, poor self-concept, association with delinquent peers, drug use, physical and sexual abuse, poor parenting, truancy, and poor educational performance (Archwamety \& Katsiyannis, 2000; Ball \& Connolly, 2000; Carr \& Vandiver, 2001; Chesney-Lind \& Sheldon, 1992; Goff \& Goddard, 1999; Matza, 1964; Stoiber, 1998; Tanner, Davies, \& O’Grady, 1999; Waytowich \& Onwuegbuzie, 2007; Welsh, Stokes, \& Greene, 2000), scant research has been paid attention to predictors of violence attribution errors. Because violence attribution errors have been found to predict acts of violence (Daley \& Onwuegbuzie, 2002/2003), it is expected that identifying antecedents of violence attribution errors likely would increase our understanding of why adolescents engage in delinquent behaviors in general and acts of violence in particular. The present study was unique for at least two reasons. First, the current investigation was the first to 
investigate violence attribution errors committed by female juvenile delinquents. In addition, it represented the only study in which male and female juvenile delinquents have been compared with respect to these attribution errors.

The relevance of researching female delinquency is especially pertinent to the state of Florida. Inasmuch as the representation of females in Florida's Juvenile Justice system is growing, the 2001-2002 statistics were somewhat more encouraging, with females accounting for less than $30 \%$ of all juvenile delinquency referrals. However, between 1998-1999 and 2002-2003 female residential placements increased $25.2 \%$, resulting in a greater number of girls placed in commitment programs for violent offenders (Florida Department of Juvenile Justice, 2006).

\section{Method}

\subsection{Participants}

Participants were 181 juvenile delinquents, comprising 51 females (28.2\%) and 130 males (71.8\%). Participants participated in two delinquency intervention programs initiated in Florida during the 2005-2006 year. The sample size was selected via an a priori power analysis because it provided acceptable statistical power-that is, a power coefficient of .80 or greater-for detecting a statistically significant multiple regression model containing 19 predictor variables (i.e., 2 attitude toward violence variables, 4 peer victimization variables, 12 self-image variables, 1 demographic variable) with a medium effect size $\left(R^{2}=.15\right)$ at a $5 \%$ level of significance (Erdfelder, Faul, \& Buchner, 1996). Ages of the participants ranged from 12 to $16(M=14.60, S D=1.05)$. The participants represented all adolescents who participated in those programs.

\subsection{Instruments}

Participants were administered the following four instruments: (a) Violence Attribution Scale (VAS; Daley \& Onwuegbuzie, 2004); (b) Attitudes Toward Violence (ATVS; Daley \& Onwuegbuzie, 1995); (c) Offer Self-Image Questionnaire (OSIQ; Offer, Ostrov, \& Howard, 1984); and (d) Multidimensional Peer-Victimization Scale (Mynard \& Joseph, 2000). Participant demographic information was extracted from the Juvenile Justice Information System (JJIS). According to Onwuegbuzie and Daniel (2004), score reliabilities should be reported not only for the full sample but also for any major subgroups to ensure that each instrument yields scores that are adequately reliable for each subgroup. Because females and males were the major subgroups in the present investigation, score reliability is reported for each instrument as a function of gender, as well as for the full sample.

Violence Attribution Scale (VAS; Daley \& Onwuegbuzie, 2004: The VAS is a 12-item questionnaire designed to assess attributions assigned by the juveniles for the behavior of others involved in a variety of violent acts. Each item consists of a vignette, followed by three possible attributions (i.e., person, stimulus, and circumstance) that are presented in multiple-choice format, and an open-ended question asking the juveniles to indicate their reasons for choosing the response that they did. The vignettes were constructed in such a way as to allow for the perceived plausibility of any one of the three possible attributions. Because 
stimulus and circumstance responses represent attribution errors on the VAS, these two responses should be combined and contrasted to person attributions. These externally attributed responses (i.e., stimulus and circumstance) should be compared to responses signifying dispositional attributions (i.e., person), such that external attributions receive a score of 1 and dispositional attributions receive a score of 0 . Responses to the 12 items of the VAS are summed to produce an index of violence attribution errors (range $=0-12$ ). High scores suggest that subjects commit a high proportion of attribution errors. Daley and Onwuegbuzie (2004) reported VAS scores that yielded a classical theory alpha reliability coefficient of .71 (95\% confidence interval $[\mathrm{CI}]=.61, .79)$. For the present study, coefficient alpha was $.74(95 \% \mathrm{CI}=.68, .79)$. With respect to content-related validity, the VAS was reviewed by secondary school teachers and analyzed using Grammatik 5 (Reference Software International, 1992) for readability. The scale was found to be suitable for readers at a fifth-grade level. With regard to construct-related validity, a factor analysis conducted by the authors revealed a single factor, thereby justifying that total scale scores be used. Local norms for the VAS are available from the instrument developers. For the current study, the score reliability estimates of the VAS was $.80(95 \%$ Confidence Interval $[\mathrm{CI}]=.71, .87)$ for females, $.70(95 \% \mathrm{CI}=.62, .77)$ for males, and $.74(95 \% \mathrm{CI}=.68, .79)$ for the total sample.

Attitudes toward Violence-ATVS (Daley \& Onwuegbuzie, 1995): The ATVS is a 16-item instrument designed to assess the juveniles' attitudes toward verbal, sexual, and physical acts of aggression in both passive and active contexts. Each item represents of a hypothetical situation, followed by 5-point Likert-type scale. The juveniles are asked to (a) assess the degree of violence act (i.e., $0=$ never, $4=$ very violent), and (b) report the frequency with which they would engage in similar behavior if they were sure of not being punished (i.e., $0=$ never, $4=$ always). Thus, the ATVS contains two 16-item scales-namely, attitudes toward the violent acts of others and attitudes toward one's own violent act, respectively-with scores on each scale ranging from 0 to 64 . High scores on the first scale indicate non-tolerant attitudes toward the violent acts committed by others. Conversely, high scores on the second scale indicate tolerant attitudes toward committing one's own violent acts. Daley and Onwuegbuzie (1995) reported ATVS scores that yielded a classical theory alpha reliability coefficient of .75 (95\% $\mathrm{CI}=.63, .81$ ). Local norms for the ATVS are available from the instrument developers. For the present investigation, the score reliability estimates of the first part of the ATVS was .86 $(95 \% \mathrm{CI}=.80, .91)$ for females, $.84(95 \% \mathrm{CI}=.80, .88)$ for males, and .84 (95\% CI $=.80, .87)$ for the total sample. The score reliability estimates of the second part of the ATVS was .90 $(95 \% \mathrm{CI}=.85, .94)$ for females, $.90(95 \% \mathrm{CI}=.87, .92)$ for males, and $.90(95 \% \mathrm{CI}=.88, .92)$ for the total sample.

Offer Self-Image Questionnaire-OSIQ (Offer et al., 1984): The OSIQ is a 130-item Likert-format instrument compromising 12 subscales that measure adolescents functioning across multiple aspects of life, namely: impulse control, emotional tone, body image, social relationships, morals, sexual attitudes, family relationships, mastery, vocational and educational goals, emotional health, superior adjustment, and idealism. High scores on any of the subscales indicate positive self-image. Normative data exist for delinquent adolescents. Alpha reliability coefficients for OSIQ scores reported by the developers ranged from .45 to .84 for the scale 
scores (Offer et al., 1984). For the current inquiry, the score reliability estimates of the OSIQ subscales for males, females, and the total sample, are displayed in Table 1.

Table 1. Score Reliability Estimates (and 95\% Confidence Intervals) by Gender for the Offer Self-Image Subscales

\begin{tabular}{llcc} 
Subscale & Females & Males & Total Sample \\
\hline Impulse Control & $.54(.32, .71)$ & $.63(.53, .72)$ & $.60(.51, .68)$ \\
Emotional Tone & $.44(.18, .64)$ & $.59(.48, .69)$ & $.55(.45, .64)$ \\
Body Image & $.69(.54, .80$ & $.73(.65, .79)$ & $.73(.67, .79)$ \\
Social Relationships & $.54(.32, .71)$ & $.66(.56, .74)$ & $.63(.54, .71)$ \\
Morals & $.39(.11, .61)$ & $.41(.25, .55)$ & $.42(.29, .54)$ \\
Sexual Attitudes & $.53(.31, .70)$ & $.52(.39, .63)$ & $.53(.42, .63)$ \\
Family Relationships & $.77(.67, .85)$ & $.82(.77, .86)$ & $.81(.77, .85)$ \\
Mastery & $.60(.41, .75)$ & $.66(.57, .74)$ & $.64(.56, .71)$ \\
Vocational and Educational Goals & $.62(.44, .76)$ & $.75(.68, .81)$ & $.71(.64, .77)$ \\
Emotional Health & $.64(.48, .77)$ & $.72(.64, .79)$ & $.71(.64, .77)$ \\
Superior Adjustment & $.32(.01, .57)$ & $.47(.33, .59)$ & $.43(.30, .54)$ \\
Idealism & $.27(.0, .54)$ & $.18(0, .38)$ & $.21(.02, .38)$
\end{tabular}

Multidimensional Peer-Victimization Scale (Mynard \& Joseph, 2000): The Multidimensional Peer-Victimization Scale is a 16-item instrument designed to assess peer-victimization. Aspects of victimization include negative physical actions (e.g., punched, kicked), negative verbal actions (e.g., made fun of me for some reason, swore at me), social manipulation (e.g., tried to make my friends turn against me), and delinquent attacks on property (e.g., tried to break something of mine). Each item is rated on a 3-point Likert-format scale, ranging from 0 to 2 (i.e., $0=$ not at all, 1 = once, 2 = more than once). This instrument contains four main factors that were revealed via an oblique principal component analysis: physical victimization, verbal victimization, social manipulation, and attacks on property. The overall total score ranges from 0 to 32 and for each domain from 0 to 8, with higher scores representing greater victimization. Mynard and Joseph (2000) reported score reliability coefficients (Cronbach's alpha) of .85 for physical victimization, .75 for verbal victimization, .77 for social manipulation, and .73 for attacks on property. Evidence of convergent validity was provided via the finding that victims of bullying scored statistically significantly higher on each of the four subscales than did their non-victimized counterparts. For the present study, the score reliability estimates for the physical victimization subscale was $.73(95 \% \mathrm{CI}=.58, .83)$ for females, .82 (95\% CI $=.76, .87)$ for males, and $.80(95 \% \mathrm{CI}=.75, .84)$ for the total sample; for the verbal victimization subscale was $.85(95 \% \mathrm{CI}=.77, .91)$ for females, $.75(95 \% \mathrm{CI}=.67, .81)$ for males, and $.78(95 \% \mathrm{CI}=.72, .83)$ for the total sample; for the social manipulation subscale was $.84(95 \% \mathrm{CI}=.75, .90)$ for females, $.71(95 \% \mathrm{CI}=.62, .78)$ for males, and $.76(95 \% \mathrm{CI}$ $=.70, .81)$ for the total sample; and for the attacks on property subscale was .83 (95\% CI $=.74, .90)$ for females, $.82(95 \% \mathrm{CI}=.76, .87)$ for males, and $.83(95 \% \mathrm{CI}=.79, .87)$ for the total sample. 


\section{Results}

Table 2 presents the number and proportion of violence attribution errors. It can be seen from Table 2 that, for the sample as a whole, the mean number of attribution errors was 6.11 . That is, on average, the juvenile delinquents were committing attribution errors $51.04 \%$ of the time. This suggests a moderate-to-large effect size. For the female adolescents, the mean number of attribution errors was 5.64, indicating that they were committing attribution errors $46.99 \%$ of the time, on average. For the male adolescents, the mean number of attribution errors was 6.33, which corresponded to an violence attribution error rate of $52.73 \%$.

Table 2. Number and Proportion of Violence Attribution Errors by Gender

\begin{tabular}{|c|c|c|c|c|c|c|c|c|}
\hline & $M$ & $S D$ & $\begin{array}{l}\text { Lower 95\% } \\
\text { Confidence } \\
\text { Interval }\end{array}$ & $\begin{array}{l}\text { Upper 95\% } \\
\text { Confidence } \\
\text { Interval }\end{array}$ & $M$ & $S D$ & $\begin{array}{l}\text { Lower 95\% } \\
\text { Confidence } \\
\text { Interval } \\
\end{array}$ & $\begin{array}{l}\text { Upper 95\% } \\
\text { Confidence } \\
\text { Interval }\end{array}$ \\
\hline Female & 5.64 & 2.96 & 4.77 & 6.51 & 46.99 & 24.66 & 39.75 & 54.23 \\
\hline Male & 6.33 & 2.47 & 5.87 & 6.79 & 52.73 & 20.61 & 48.89 & 56.57 \\
\hline Total & 6.11 & 2.63 & 5.71 & 6.54 & 51.04 & 21.95 & 47.61 & 54.47 \\
\hline
\end{tabular}

An examination of responses to each item on the VAS revealed that whereas more than $50 \%$ of the male juvenile delinquents made violence attribution errors on 7 of the 12 scenarios of the VAS, more than $50 \%$ of the female juvenile delinquents made violence attribution errors on 5 of these scenarios. A series of Fisher's exact tests was conducted to compare the responses of the male and female juvenile delinquents for each item. The Bonferroni adjustment was used to control for familywise error $(p<.05)$. Findings revealed that in none of the 12 VAS scenarios did a statistically significantly smaller proportion of the female juvenile delinquents make violence attribution errors than did the male juvenile delinquents. In fact, although not statistically significant, a larger proportion of female delinquents made violence attribution errors compared to their male counterparts on 4 of the 12 scenarios.

According to Onwuegbuzie and Daniel (2002), variables for which either the standardized skewness coefficient (i.e., skewness coefficient divided by its standard error) or the standardized kurtosis coefficient (i.e., kurtosis coefficient divided by its standard error), or both, are outside the $\forall 3$ range suggest extreme departure from normality. An examination of the skewness and kurtosis coefficients pertaining to the VAS scores revealed no departure from normality for either gender. For females both the standardized skewness (0.26) and standardized kurtosis (-0.51) coefficients were much less than 3.00, as was the case for males (i.e., standardized skewness $=-1.17$; standardized kurtosis $=-0.58$ ), thereby justifying use of the independent samples $t$-test. Although the violence attribution error rate was lower for females than for males, the independent samples $t$-test revealed no statistically significant 
difference $(t=1.51, p>.05)$.

Because no statistically significant differences emerged between the female and male juvenile offenders, their VAS responses were combined. An examination of the histogram pertaining to the VAS scores for the total sample indicated no serious departure from normality. Consistent with this interpretation, both the standardized skewness (-0.93) and standardized kurtosis (-0.83) coefficients were within the range of normality (Onwuegbuzie \& Daniel, 2002). Further, the Shapiro-Wilk test (Shapiro \& Wilk, 1965; Shapiro, Wilk, \& Chen, 1968) did not indicate that the distribution of group performance scores was non-normal ( $W=.98, p>.05$ ), thereby justifying the use of multiple regression. In addition, evaluation of assumptions of linearity and homogeneity indicated no threat to multiple regression analysis. In the multiple regression analysis, the number of violence attribution errors served as the dependent variable, whereas the independent variables comprised attitudes toward violence (i.e., attitudes toward the violent acts of others, attitude toward one's own violent act), level of peer-victimization (i.e., physical victimization, verbal victimization, social manipulation, and attacks on property), self-image (i.e., impulse control, emotional tone, body image, social relationships, morals, sexual attitudes, family relationships, mastery, vocational and educational goals, emotional health, superior adjustment, and idealism), and one demographic variable (i.e., race; White vs. African American). As such, the multiple regression analysis involved 19 independent variables.

The multiple regression analysis involved only juvenile delinquents for whom scores for all 19 measures were available. Thus, 109 juveniles were utilized for this analysis. The results of the multiple regression analysis are provided in Table 3. It can be seen from this table that the multiple regression model was statistically significant $(F[19,89]=2.10, p=.01)$. The 19 variables combined explained $30.9 \%$ of the variance. An examination of the standardized regression coefficients and $t$-values revealed that six variables statistically significantly predicted the number of violence attribution errors: attitude toward the violent acts of others, attitude toward one's own violent acts, verbal victimization, attacks on property, emotional health, and race. An examination of the studentized residuals generated from the model (Myers, 1986) suggested that the assumptions of normality, linearity, and homoscedasticity were met. Using the Bonferroni adjustment, none of the studentized residuals suggested that outliers were present.

The purpose of this study was threefold: (a) to assess the prevalence of violence attribution errors among female adolescent delinquents, (b) to compare female delinquents' violence attribution error rate to that of their male counterparts who were participating in the same delinquency intervention programs, and (c) to identify predictors (i.e., attitudes toward violence, peer victimization, self-esteem, demographic variables) of violence attribution errors.

Incidentally, the results indicated that females did not make statistically significantly less violence attribution errors than did their male counterparts both overall and on a scenario-by-scenario basis. Specifically, female delinquents made attribution errors approximately $47 \%$ of the time, whereas the male delinquents made attribution errors approximately $53 \%$ of the time-yielding a $6 \%$ mean difference. Notably, this attribution 
error rate for males was identical to that reported by Daley and Onwuegbuzie (2004) and Onwuegbuzie, Daley, and Waytowich (2008), adding incremental validity to this finding.

Table 3. Multiple Regression Analysis for Predicting Violence Attribution Errors: Unstandardized Coefficient, Standardized Coefficients, and t-Values

\begin{tabular}{|c|c|c|c|}
\hline Subscale & $\begin{array}{c}\text { Unstandardized } \\
\text { Coefficient } \\
\text { (Standard Error) }\end{array}$ & $\begin{array}{c}\text { Standardized } \\
\text { Coefficient } \\
(\beta) \\
\end{array}$ & $t$ \\
\hline Constant & $7.50(2.69)$ & - & $2.79 *$ \\
\hline \multicolumn{4}{|l|}{ ATVS: } \\
\hline Attitudes Toward the Violent Acts of Others & $-0.08(0.03)$ & -0.32 & $-3.04 *$ \\
\hline Attitudes Toward One’s Own Violent Acts & $0.05(0.02)$ & 0.23 & 2.09* \\
\hline \multicolumn{4}{|l|}{ MPVS: } \\
\hline Physical Victimization & $0.01(0.14)$ & 0.01 & 0.05 \\
\hline Verbal Victimization & $-0.27(0.12)$ & -0.27 & $-2.16^{*}$ \\
\hline Social Victimization & $-0.05(0.15)$ & -0.04 & -0.32 \\
\hline Attacks on Property & $0.28(0.14)$ & 0.25 & $1.94 *$ \\
\hline \multicolumn{4}{|l|}{ OSIQ: } \\
\hline Impulse Control & $-0.02(0.05)$ & -0.07 & -0.48 \\
\hline Emotional Tone & $-0.01(0.06)$ & -0.02 & -0.11 \\
\hline Body Image & $0.09(0.05)$ & 0.29 & 1.75 \\
\hline Social Relationships & $0.08(0.06)$ & 0.24 & 1.50 \\
\hline Morals & $-0.03(0.04)$ & -0.08 & -0.74 \\
\hline Sexual Attitudes & $-0.03(0.04)$ & -0.09 & -0.74 \\
\hline Family Relationships & $0.01(0.02)$ & 0.06 & 0.48 \\
\hline Mastery & $-0.05(0.05)$ & -0.14 & -0.92 \\
\hline Vocational and Educational Goals & $0.05(0.05)$ & 0.15 & 0.95 \\
\hline Emotional Health & $0.01(0.04)$ & 0.02 & 0.11 \\
\hline Superior Adjustment & $-0.09(0.04)$ & -0.27 & $-2.01^{*}$ \\
\hline Idealism & $0.01(0.06)$ & 0.03 & 0.26 \\
\hline \multicolumn{4}{|l|}{ Demographic: } \\
\hline Race (i.e., White vs. African American) & $1.19(0.54)$ & 0.22 & $2.20 *$ \\
\hline
\end{tabular}

$$
\begin{aligned}
{ }^{*} p & <.05 \\
R^{2} & =30.9 \%, F(19,89)=2.10, p=.01
\end{aligned}
$$

The finding of no gender difference in violence attribution errors suggests that female 
delinquents are as likely to make causal misattributions when appraising the violent actions of others as are male delinquents. Bearing in mind the fact that violence attribution errors is significantly associated with risk factors and could lead to violent attitudes, experiences, or hostile behaviors, including believing that men have a right to expect sex from women, having friends who died violently, and bringing a gun to school (Daley \& Onwuegbuzie, 2002/2003), the present finding highlighting the lack of gender differences in the development of violence attribution errors, which suggests female delinquents might be as much at risk for committing anti-social interaction as are their male counterparts. Interestingly, this finding is somewhat at odds with Daley and Onwuegbuzie (1999), who reported that females in their earlier sample tended to make significantly fewer violence attribution errors than did their male counterparts. Whereas the earlier study (i.e., Daley \& Onwuegbuzie, 1999) focused on high school students with no criminal records, the present study examined youths who had been arrested on at least two occasions. The evidence that the gap in the rate of violence attribution errors between females and males might narrow dramatically for offender populations has intuitive appeal and suggests that female offenders are likely to engage in more violence attribution errors than are female non-offenders. Such explanation is difficult to rule out, and this difference, in turn, might help to explain, at least in part, why some, if not most, of the current female study participants had come into contact with the law. Indeed, the available evidence suggest that propensity to commit violence attribution errors - if it persists-may interfere with normal interaction and can potentially lead to disadvantaged health and behavior conditions (Daley \& Onwuegbuzie, 1999), leading to their eventual arrest. This possible link between a female child's or adolescent's commission of violence attribution errors and possible future arrest is a crucial issue and should be a subject of further investigation.

The multiple regression model identified clear predictors of violence attribution errors including attitude toward the violent acts of others, attitude toward one's own violent acts, verbal victimization, attacks on property, emotional health, and race. It seems likely that female and male juvenile delinquents who made the most violence attribution errors tended to be the following: African American, have the most tolerant attitudes toward violent acts committed by others, have the least tolerant attitudes toward committing one's own violent acts, have the lowest levels of self-image associated with superior adjustment, have experienced the most peer-victimization associated with attacks on property, and have experienced the least verbal victimization. More recent studies have began to examine race differences in committing violence attribution errors (Daley \& Onwuegbuzie, 2004). As noted by these researchers, this significant finding likely reflects the different experiences between these two populations. According to Dodge and Tomlin (1983), aggressive youngsters are more likely to depend on past experiences than are their non-aggressive peers when making interpreting the behavior of other people. Thus, level of racism, probably experienced by a large proportion of African American offenders in the current sample, to some extent, may result in African American and other minority adolescents being more sensitive about being provoked than are their White peers, as was found in both the present inquiry and that of Daley and Onwuegbuzie (2004). Race has been found to be a proxy for other risk factors such as low socioeconomic conditions, single-parent home, poor academic achievement, gangs, residing in disorganized 
neighborhoods, and exposure to community violence (Elliott, Huizinga, \& Menard, 1989; Reiss \& Roth, 1993). Thus, violence attribution error might manifest itself through races as function of differences in social bases of power and disadvantages rather than biological differences.

Most importantly, the findings that juvenile delinquents who make the most violence attribution errors tend to have the most tolerant attitudes toward violent acts committed by others and to have the least tolerant attitudes toward committing one's own violent acts has tremendous intuitive appeal because it suggests that violent attitudes play a role in the formation of causal attributions when offenders are explaining the violent actions of others. This link might be explained partly by Ajzen's $(1985,1991,2003)$ theory of planned behavior, according to which, a behavior is best explained by intention to perform the behavior and perceived behavioral control toward the behavior. Intention, which is an immediate predictor of behavior, is explained by a set of three predictors — one of which is one's attitudes toward a behavior. Thus, it is likely that attitudes toward a behavior such as a violent act serves as an antecedent for the intention to perform that behavior, in this case a violent act, which, in turn, facilitates that behavior (i.e., violent act). Furthermore, violent or other anti-social behaviors that result from inappropriate attitudes toward violence that may lead to violence attribution errors may be partially predicted by Aizen's (1985, 1991, 2003) and Aizen and Fishbein's (1980) theory of planned behavior. Thus, future studies should explore further the role that Ajzen's theory can play in the area of violence attribution errors.

The present findings suggest that juvenile offenders who make the most violence attribution errors tend to have the lowest levels of self-image; thus, perceived self esteem, or lack thereof, serve as a viable predictor of potential violence (Branden, 1994; Sutherland \& Shepherd, 2002). In accordance with Daley and Onwuegbuzie's (2004) findings linking violence attribution errors to at-risk youth behaviors and the existing data that support a relationship between self-image and aggressive behaviors (Branden, 1994; Kaplan, Martin, \& Robbins, 1982; Slaby \& Guerra, 1988; Sutherland \& Shepherd, 2002), for the current study, it is likely that violence attribution errors serve as a cognitive mediator between self-image and at-risk behaviors, specifically, violence. Within this line of thought, current literature generally agrees that cognitive appraisals of an individual's personal attributes are instrumental mechanism in the formation of self-concept (Hattie, 1992). Further, attribution processes have been found to be a contributor to children's reactions to violence (Guthrie \& Betancourt, 1999). Subsequently, low self-esteem and the commission of violence attribution errors may both singularly and interactively be pathways to at-risk behaviors-especially violence (Daley \& Onwuegbuzie, 2004) - when low self esteem is reduced as a result of inaccurate causal inferences (Kelley, 1973), and because low self-esteem fails to buffer individuals against violence (Sutherland \& Shepherd, 2002).

The relationship between juvenile delinquents who make the most violence attribution errors and those who have experienced the most peer-victimization associated with attacks on property can be explained, in part, by the findings of Daley and Onwuegbuzie (2004). These researchers documented that following negative encounters, juvenile delinquents tend to view themselves as victims, and internalize negative emotions, with the youth seeing their anti-social behaviors arise 
as a result of provocation. Further, the homogeneity of victim-offender populations (Singer, 1981) suggests that juveniles are more likely to be both victim and offender as a result of the demographics of the juvenile offender population, resulting in an increased probability of victim-offender interactions. As such, youth who have been victimized by peers may process and construct social information differently than do those youth who have not had anti-social experiences (Crick \& Grotpeter, 1996; Little, Jones, Henrich, \& Hawley, 2003).

In this study, the finding that juvenile offenders who make the most violence attribution errors tend to have experienced the least verbal victimization is most puzzling. Drawing on the work of Wenninger and Anke (1998), it is plausible to concede that victimized youth may process information through a distorted lens as a result of a dysfunctional belief system (Wenninger \& Anke, 1998), thereby culminating in inaccurate causal inferences. However, a full account of the role of violence attribution errors in verbal victimization may find its explanation in the literature on labeling. Becker (1963) suggests that individuals who have been assigned the label of delinquent find associations with other individual's with the same label. Singer (1981) acknowledges that due to their similar demographics, juveniles are more likely to interact with an individual that is either a victim or a peer as a result of their daily interactions and their increased availability to each other. As a result, this may lead to a desensitization of verbal victimization. For instance, if the peer group of an offender engages in routine verbal denigration among its members, ultimately these nomenclatures may either become associated as normal group dialogue or the labels may take on new meaning (Vold, Bernard, \& Snipes, 1998), whereby the members are desensitized to the accepted societal definition making the youth unaware when a verbal assault occurs. This would explain the offender cognitive perception/appraisal of having limited experiences of verbal victimizations, as is unlikely that an adolescent offender has journeyed through a school year without ever being called a name by a peer, being sworn at by a peer, or being made fun of for any reason. In any case, the saliency of violence attribution error and its relationship to incidence of peer victimization should provide the basis for future studies.

\section{Conclusion}

The present study was unique for at least two reasons. First, the current investigation was the first to investigate violence attribution errors committed by female juvenile delinquents. In addition, there is a void in the social psychological literature as to how male and female juvenile delinquents utilize these attribution errors. A careful review of research literature on violence indicates that numerous variables exist that contribute to an adolescent's propensity towards violence (Archwamety \& Katsiyannis, 2000; Ball \& Connolly, 2000; Carr \& Vandiver, 2001; Chesney-Lind \& Sheldon, 1992; Goff \& Goddard, 1999; Matza, 1964; Stoiber, 1998; Sutherland \& Shepherd, 2002; Tanner et al., 1999; Waytowich \& Onwuegbuzie, 2007; Welsh et al., 2000). Inasmuch as self-esteem and peer-victimization are useful constructs in predicting adolescent violence (Egan \& Perry, 1998; Kaplan et al., 1982; Sutherland \& Shepherd, 2002), the current research suggests that violence attribution errors may mediate the relationship between self-esteem and at-risk behaviors, in addition to the association between peer-victimization and at-risk behaviors. Increased attention to the attribution styles of at-risk youth in the phenomenon of female juvenile delinquents may have 
implications for future juvenile justice intervention programming. This research leads to the conclusion that violence intervention programming would be more effective utilizing proactive strategies versus reactive sanctions in addressing youth violence. A thorough understanding of the inaccurate causal inferences that contribute to low self-esteem and/or violence attribution errors, juvenile interventions would address one of the underlying pathways of adolescent violence. Nevertheless, replications of this study are needed to investigate further the interplay among self-esteem, attitudes towards violence, peer-victimization, and violence attribution errors as an antecedent to violence.

\section{References}

Abramson, L. Y., Seligman M. E. P., \& Teasdale J. D. (1978) Learned helplessness in humans: Critique and reformulation. Journal of Abnormal Psychology, 87, 49-74. doi:10.1037//0021-843X.87.1.49

Ajzen, I. (1985). From intentions to actions: A theory of planned behavior. In J. Kuhl \& J. Beckmann (Eds.), Action control, from cognition to behavior (pp. 11-39). New York, NY: Springer-Verlag.

Ajzen, I. (1991). The theory of planned behavior. Organizational Behavior and Human Decision Processes, 50, 179-211. doi:10.1016/0749-5978(91)90020-T

Ajzen, I. (2003). Theory of planned behavior (TpB). [Online] Available: http://www.people.umass.edu/aizen/tpb.html

Ajzen, I., \& Fishbein, M. (1980). Understanding attitudes and predicting social behavior. Englewood Cliffs, N.J.: Prentice-Hall.

Archwamety, T., \& Katsiyannis, A. (2000). Academic remediation, parole violations, and recidivism rates among delinquent youths. Remedial and Special Education, 21, 161-170. doi:10.1177/074193250002100306

Arnold, M. (1962). Story sequence analysis. New York, NY: Holt, Rinehart \& Winston.

Ball, C., \& Connolly, J. (2000). Educationally disaffected young offenders. British Journal of Criminology, 40, 594-616. doi:10.1093/bjc/40.4.594

Becker, H. (1963). Outsiders: Studies in the sociology of deviance. New York, NY: The Free Press.

Branden, N. (1969). The psychology of self-esteem. Los Angeles, CA: Nash. Branden, N. (1994). Six pillars of self-esteem. New York, NY: Bantam.

Bulman, R., \& Wortman, C. B. (1977). Attributions of blame and coping in the "real world": Severe accident victims react to their lot. Journal of Personality and Social Psychology, 35, 351-363. doi:10.1037//0022-3514.35.5.351

Burger, J. M. (1981). Motivational biases in the attribution of responsibility for an accident: A meta-analysis of the defensive-attribution hypothesis. Psychological Bulletin, 90, 496-512. doi:10.1037//0033-2909.90.3.496 
Carr, M., \& Vandiver, T. (2001). Risk and protective factors among youth offenders. Adolescence, 36, 409-426.

Chesney-Lind, M. (2001). What about the girls? Delinquency programming as if gender Mattered. Corrections Today, 63(1), 38-45.

Chesney-Lind, M., \& Sheldon, R. (1992). Girls, delinquency and juvenile justice. Belmont, CA: Brooks/Cole.

Commission for the Prevention of Youth Violence. (2000). Youth and violence-Medicine, nursing and public health: Connecting the dots to prevent violence. [Online] Available: http://www.ama-assn.org/ama/upload/mm/386/fullreport.pdf

Crick, N., \& Grotpeter, J. (1996). Relational aggression, overt aggression, and friendship. Child Development, 67, 2328-2338.

Daley, C. E., \& Onwuegbuzie, A. J. (1995, April). Attitudes and attributions of male juvenile offenders. Paper presented at the annual meeting of the American Educational Research Association, San Francisco, CA.

Daley, C. E., \& Onwuegbuzie, A. J. (1999, April). Boys will be boys? A comparison of attributions for violence between male and female high school students. Paper presented at the annual meeting of the American Educational Research Association, Montreal, Canada.

Daley, C. E., \& Onwuegbuzie, A. J. (2002/2003). Relationship between violence attributional errors and at-risk behaviors among male juvenile delinquents. Louisiana Education Research Journal, 28(2), 3-14.

Daley, C. E., \& Onwuegbuzie, A. J. (2004). Attributions toward violence ofmale juvenile delinquents: A concurrent mixed methods analysis. Journal of Social Psychology, 144, 549-570. doi:10.3200/SOCP.144.6.549-570

Dodge, K. A., \& Tomlin, A. (1983). The role of cue-utilization in attributional biases among aggressive children. Unpublished manuscript, Indiana University.

Egan, S. K., \& Perry, D. G. (1998). Does low self-esteem invite victimization? Developmental Psychology, 34, 299-309.

Elliott, D. S., Huizinga, D., \& Menard, S. (1989). Multiple problem youth: Delinquency, substance use and mental health problems. New York, NY: Springer-Verlag.

Erdfelder. E.. Faul. F., \& Buchner. A. (1996). GPOWER: A general power analysis program. Behavior Research Methods, Instruments, \& Computers. 28, 1-11. doi:10.3758/BF03203630

Federal Interagency Forum on Child and Family Statistics. (2005). America's Children: Key National Indicators of well-being. [Online] Available: http://www.childstats.gov/americaschildren/index.asp

Fincham, F., Beach, S., \& Baucom, D. (1987). Attribution processes in distressed and nondistressed couples: 4. Self-partner attribution differences. Journal of Personality and 
Social Psychology, 52, 739-748. doi:10.1037//0022-3514.52.4.739

Fiske, S. T. (2000). Stereotyping, prejudice, and discrimination at the seam between the centuries: evolution, culture, mind, and brain. European Journal of Social Psychology, 30, 299-322. doi:10.1002/(SICI)1099-0992(200005/06)30:3<299::AID-EJSP2>3.0.CO;2-F

Florida Department of Juvenile Justice. (2006). Key juvenile crime trends and conditions. [Online] Available: http://www.djj.state.fl.us/Research/Trends.html

Fondacaro, M., \& Heller, K. (1990). Attributional style in aggressive adolescent boys. Journal of Abnormal Child Psychology, 18(1), 75-89. doi:10.1007/BF00919457

Goff, B., \& Goddard, H. (1999). Terminal core values associated with adolescent problem behaviors. Adolescence, 34(133), 47-60.

Grills, A. E., \& Ollendick, T. H. (2002). Peer victimization, global self-worth, and anxiety in middle school children. Journal of Clinical Child and Adolescent Psychology, 31, 59-68. doi:10.1207/153744202753441675

Guthrie, I., \& Betancourt, H. (1999, April). Examination of an attribution-emotion model of reactions to violence in children. Paper presented at the biennial meeting of the Society for Research in Child Development, Seattle, WA.

Hattie, J. A. (1992). Self-concept. Mahwah, NJ: Laurence Erlbaum.

Heider, F. (1958). The psychology of interpersonal relations. New York, NY: Wiley.

Herrenkohl, T., Hill, K., Chung, I., \& Catalano, R. F. (2004). Review of research on predictors of youth violence and school-based and community-based prevention approaches. In P. Allen-Meares \& M. W. Fraser (Eds.), Intervention with children and adolescents: An interdisciplinary perspective. Boston, MA: Allyn \& Bacon.

Janoff-Bulman, R. (1979). Characterlogical versus behavioral self-blame: Inquires into depression and rape. Journal of Personality and Sociology Psychology, 37, 1798-1809. doi:10.1037//0022-3514.37.10.1798

Janoff-Bulman, R., \& Frieze, I. H. (1983). A theoretical perspective for understanding reactions to victimization. Journal of Social Issues, 39(2), 1-17. doi:10.1111/j.1540-4560.1983.tb00138.x

Jones, E. E., \& Harris, V. A. (1967). The attribution of attitudes. Journal of Experimental Social Psychology, 3, 1-24. doi:10.1016/0022-1031(67)90034-0

Jones, E. E., \& Nisbett, E. (1972). The actor and the observer. Divergent perceptions of the causes of behavior. In E. E. Jones, D. Kanouse, H. H. Kelley, R. E. Nisbett, S. Valins, \& B. Weiner (Eds.), Attributions: Perceiving the causes of behavior (pp. 79-94). Morristown, NJ: General Learning Press.

Kahneman, D., Paul Slovic, P., \& Tversky, A. (Eds.) (1982). Judgement under uncertainty: Heuristics and biases. New York, NY: Cambridge. 
Kaplan, H. B., Martin, S., \& Robbins, C. (1982). Application of a general theory of deviant behavior: Self-derogation and drug use. Journal of Health and Social Issue, 23, 274-294.

Kelley, H. (1973). The processes of causal attribution. American Psychologist, 28, 107-128.

Lazarus, R. S., \& Launier, R. (1978) Stress-related transactions between person and environment. In L. A. Pervin \& M. Lewis (Eds.), Perspectives in interactional psychology (pp. 287-327). New York, NY: Plenum.

Lerner, M. J. (1970). The desire for justice and reactions to victims. In J. Macaulay \& L. Berkowitz (Ed.), Altruism and helping behavior (pp. 205-229). NewYork, NY: Academic Press.

Lerner, M. J. (1980). The belief in a just world: A fundamental delusion. New York, NY: Plenum.

Little, T., Jones, S., Henrich, C., \& Hawley, P. (2003). Disentangling the "whys" from the "whats" of aggressive behavior. International Journal of Behavioral Development, 27, 122-133. doi:10.1080/01650250244000128

Matza, D. (1964). Delinquency and drift. New York, NY: Wiley.

Myers, R.H. (1986). Classical and modern regression with applications. Boston, MA: Duxbury Press.

Mynard, H., \& Joseph, S. (2000). Development of the multidimensional peer-victimization scale. Aggressive Behavior, 26, 169-178. doi:10.1002/(SICI)1098-2337(2000)26:2<169:: AID-AB3>3.3.CO;2-1

Nisbett, R. E., \& Ross, L. (1980). Human inference: Strategies and shortcomings ofsocial judgment. Englewood Cliffs, NJ: Prentice-Hall.

Offer, D., Ostrov, E., \& Howard, K. (1984). The self-image of normal adolescents. New Directions for Mental Health Services, 22, 5-17. doi:10.1002/yd.23319842203

Onwuegbuzie, A. J., \& Daniel, L. G. (2002). Uses and misuses of the correlation coefficient. Research in the Schools, 9(1), 73-90.

Onwuegbuzie, A. J., \& Daniel, L. G. (2004). Reliability generalization: The importance of considering sample specificity, confidence intervals, and subgroup differences. Research in the Schools, 11(1), 60-71.

Onwuegbuzie, A. J., Daley, C. E., \& Waytowich, V. L. (2008). A mixed methods investigation of male juvenile delinquents' attributions toward violence. Journal of At-Risk Issues, 14(1), 1-11

Reference Software International. (1992). Grammatik 5.0 for DOS (4th ed.) [Computer software].

Reiss, A. J. Jr., \& Roth, J. A. (1993). Understanding and preventing violence. Washington, DC: National Academy Press. 
Shapiro, S. S., \& Wilk, M. B. (1965). An analysis of variance test, for normality and complete samples. Biometrika, 52, 592-611.

Shapiro, S. S., Wilk, M. B., \& Chen, H. J. (1968). A comparative study of various tests for normality. Journal of the American Statistical Association, 63, 1343-1372. doi:10.2307/2285889

Shaver, K.G., \& Drown, D. (1986). On causality, responsibility, and self-blame: A theoretical note. Journal of Personality and Social Psychology, 50, 697-702. doi:10.1037//0022-3514.50.4.697

Silver, R., Wortman, C. \& Klos, D. (1982). Cognitions, affect and behavior following uncontrollable outcomes: A response to current human helplessness research. Journal of Personality, 50, 480-514. doi:10.1111/j.1467-6494.1982.tb00230.x

Singer, S. I. (1981). Homogeneous victim-offender populations: A review and some research implications. The Journal of Criminal Law and Criminology, 72, 779-788. doi:10.2307/1143015

Slaby, R. G., \& Guerra, N., G. (1988). Cognitive mediators of aggression in adolescent offenders: 1. Assessment. Developmental Psychology, 24, 580-588. doi:10.1037//0012-1649.24.4.580

Stoiber, K. (1998). Risk and resilience factors linked to problem behavior among urban,culturally diverse adolescents. The School Psychology Review, 27, 380-397.

Sutherland, I., \& Shepherd, J. P. (2002). A personality-based model of adolescent violence. British Journal of Criminology, 42, 433-441. doi:10.1093/bjc/42.2.433

Tanner, J., Davies, S., \& O’Grady, B. (1999). Whatever happened to yesterday’s rebels? Longitudinal effects of youth delinquency on education and employment. Social Problems, 46, 250-274. doi:10.1525/sp.1999.46.2.03x0188f

Tetlock, P. E. (1985). Accountability: A social check on the fundamental attribution error. Social Psychology Quarterly, 48, 227-236. doi:10.2307/3033683

Trachtenberg, S., \& Viken, R. J. (1994). Aggressive boys in the classroom: Biased attributions or shared perceptions? Child Development, 65, 829-835. doi:10.2307/1131421

Tversky, A., \& Kahneman, D. (1974). Judgment and uncertainty: Heuristics and biases. Science, 185, 1124-1131. doi:10.1126/science.185.4157.1124

U.S. Department of Justice, Office of Justice Programs. (1999). Women offenders. Bureau of Justice Statistics Special Report. [Online] Available: http://www.utmb.edu/imh/CorrectionalHealth/WomenOffenders.pdf

Vold, G., Bernard, T., \& Snipes, J. (1998). Theoretical criminology. New York, NY: Oxford Press.

Waytowich, V. L., \& Onwuegbuzie, A. J. (2007). Violence. In K. M. Borman, S. E. Cahill, \& 


\section{Macrothink}

International Journal of Education ISSN 1948-5476 2011, Vol. 3, No. 1: E6

B. A. Cotner (Eds.), The Praeger handbook of American high schools (pp. 429-434). Westport, CT: Praeger.

Weiner, B. (1985). “Spontaneous” casual thinking. Psychological Bulletin, 97, 74-84.

Welsh, W., Stokes, R., \& Greene, J. (2000). A macro-level of school disorder. Journal of Research in Crime and Delinquency, 37, 243-283. doi:10.1177/0022427800037003001

Wenninger, K., \& Anke, E. (April, 1998). Dysfunctional cognitions and adult psychological functioning in child sexual abuse survivors. Behavioral Science, 11, 281-300. doi:10.1023/A:1024451103931

Wortman, C. B., \& Dintzer, L. (1978). Is an attributional analysis of the learned helplessness phenomenon viable? A critique of the Abramson, Seligman, Teasdale reformulation. Journal of Abnormal Psychology, 87, 75-90. doi:10.1037/0021-843X.87.1.75

\section{Copyright Disclaimer}

Copyright reserved by the author(s).

This article is an open-access article distributed under the terms and conditions of the Creative Commons Attribution license (http://creativecommons.org/licenses/by/3.0/). 